\title{
Problemática de aprovação de PPCIP no Corpo de Bombeiros de Porto Nacional (TO)
}

Incêndios podem ocorrer de forma imprevisível e atingir edificações, causando danos à mesma, e até mesmo à vida dos ocupantes destas. Para evitar esses incêndios e preservar a segurança das pessoas, existem normas que regulamentam medidas de segurança e procedimentos que devem ser adotados na construção dos edifícios para a prevenção e combate a incêndio, onde são diferentes para cada estado brasileiro e regulamentadas por meio do Corpo de Bombeiros. Para o estado do Tocantins, há 30 Normas Técnicas vigentes que determinam as regras e medidas de segurança, onde por meio das mesmas é possível a elaboração do Projeto de Prevenção e Combate a Incêndio e Pânico - PPCIP, sendo que estas são regulamentadas por meio da Lei 1.787/2007 do Estado do Tocantins. Devido à problemática existente para a aprovação do PPCIP, este trabalho realizou uma pesquisa com todas as análises do Corpo de Bombeiros de Porto Nacional (TO) de janeiro de 2017 a março de 2019, e identificou que a grande maioria dos processos de PPCIP apresentam erros que infringem às Normas Técnicas, principalmente a NT-01 e NT-08. Além disso, foi feito um questionário com 66 estudantes e profissionais de Engenharia Civil e Arquitetura, que identificou a falta de conhecimento deles no que tange às Normas Técnicas para a elaboração de PPCIP.

Palavras-chave: Edificações; Legislação; Bombeiros; Combate a incêndio e pânico.

\section{PPCIP approval issue at the Porto Nacional Fire Department (TO)}

\begin{abstract}
Fires can occur unpredictably and hit buildings, causing damage to it, and even the lives of its occupants. To prevent these fires and preserve the safety of people there are rules that regulate safety measures and procedures that must be adopted in the construction of fire prevention and fire fighting buildings, where they are different for each Brazilian state and regulated by the Corps. Firemen. For the state of Tocantins, there are 30 current Technical Standards that determine the rules and safety measures, where through them it is possible to elaborate the Fire Prevention and Fighting and Panic Project - PPCIP, and these are regulated by the Law 1,787 / 2007 of the State of Tocantins. Due to the existing problems for PPCIP approval, this work conducted a survey of all analyzes of the Porto Nacional Fire Department (TO) from January 2017 to March 2019 and found that the vast majority of PPCIP processes have errors. that violate the Technical Standards, especially NT-01 and NT-08. In addition, a questionnaire was made with 66 students and professionals from Civil Engineering and Architecture, which identified their lack of knowledge regarding the Technical Standards for the preparation of PPCIP.
\end{abstract}

Keywords: Buildings; Legislation; Firemen; Fire fighting and panic.

Topic: Engenharia Civil

Reviewed anonymously in the process of blind peer.
Received: 07/04/2019

Approved: 08/07/2019
Jhosef Nascimento dos Santos (it)

Instituto Tocantinense Presidente Antônio Carlos, Brasil

http://lattes.cnpq.br/6713424941814318

http://orcid.org/0000-0002-6199-2651

jhosef18@yahoo.com.br

Diogo Pedreira Lima (iD

Instituto Tocantinense Presidente Antônio Carlos, Brasil

http://lattes.cnpq.br/7967728577417186

http://orcid.org/0000-0002-3849-2587

diogo.lima@itpacporto.edu.br

\section{Referencing this:}

SANTOS, J. N.; LIMA, D. P.. Problemática de aprovação de PPCIP no Corpo de Bombeiros de Porto Nacional (TO). Engineering Sciences, v.7, n.2, p.9-19, 2019. DOI: http://doi.org/10.6008/CBPC23183055.2019.002.0002 


\section{INTRODUÇÃO}

Segundo Fagundes (2013), o fogo, também chamado de combustão, é uma reação química que se ocasiona a partir de uma oxidação entre o oxigênio do ar e algum material combustível, seja ele sólido, líquido ou gasoso. Quando atinge grandes proporções, o fogo é chamado de incêndio, e pode atingir um nível fora de controle, implicando em riscos para tudo ao seu redor, incluindo os seres vivos e os edifícios (PORTUGAL, 2014). Fagundes (2013) afirma que toda edificação está sujeita a ser atingida pelo fogo, sendo esta uma calamidade imprevisível, podendo causar acidentes e muitas perdas, tanto de vidas humanas quanto de materiais, e, portanto, toda edificação deve ser projetada, sob o ponto de vista da segurança, para combater incêndios.

Segundo Gomes (2014), a prevenção e combate a incêndios é um assunto antigo. Entretanto foi necessário haver muitos incêndios, acidentes e mortes para que fossem desenvolvidos métodos, equipamentos e legislações para tal, onde atualmente existem inúmeras leis que obriga a existência de um Projeto de Prevenção e Combate a Incêndio (PPCI). Todo estado brasileiro dispõe de uma legislação específica para a regulamentação e elaboração de projetos de prevenção e combate a incêndio, que são pautadas a partir da Associação Brasileira de Normas Técnicas (ABNT), bem como em portarias e resoluções do Corpo de Bombeiros (SILVA et al., 2017).

Segundo Rocha (2016), os incêndios ocorrem, na maioria dos casos, de forma imprevisível, entretanto os mesmos podem ser evitados por meio de um sistema eficaz e eficientes de prevenção e combate a incêndios, além de pessoas capacitadas para manusear este sistema. De um modo geral, o projeto de segurança para prevenir e combater incêndios é chamado de PPCIP, e de acordo com Gomes (2014), esse projeto pode ser elaborado apenas por profissionais capacitados e habilitados, sendo eles os Engenheiros Civis e Arquitetos, e sua aprovação e fiscalização é feita a partir do Corpo de Bombeiros, através de vistorias e alvarás, que são exigidos por lei para proporcionar segurança.

Durante a graduação em Engenharia Civil e Arquitetura e Urbanismo, os acadêmicos são capacitados a realizar projetos de combate a incêndio e pânico, mas durante o exercício profissional podem haver dificuldades para a aprovação desses projetos junto ao Corpo de Bombeiros, ocorrendo erros nos projetos que os impedem de serem aprovados, devendo ser corrigidos até que tudo esteja dentro das normas vigentes. Galvão (2018) afirma que a aprovação de projetos de combate a incêndio é diferente em cada estado, visto que há legislações específicas em cada estado do território nacional, onde suas normas se diferem dos outros devido a adequação às características do local.

No Estado do Tocantins, a legislação que trata sobre a segurança contra incêndio e pânico em edificações, para nortear a elaboração de projetos, é a Lei no 1.787 de 15 de maio de 2007. Através desta lei, o Corpo de Bombeiros Militar do Estado do Tocantins estabelece as condições mínimas de segurança que as edificações precisam apresentar para obter a regularização, por meio de 32 Normas Técnicas, nas quais duas foram revogadas, totalizando 30 Normas Técnicas disponíveis, sendo elas: NT-01: Procedimentos Administrativos; NT-02: Terminologia de Proteção Contra Incêndio e Pânico; NT-03: Símbolos Gráficos para 
Projetos de Segurança contra Incêndio e Pânico; NT-04: Acesso de Viaturas nas Edificações, Locais de Aglomeração de Público e Áreas de Risco; NT-05: Separação entre Edificações (Isolamento de Risco); NT-06: Segurança Estrutural das Edificações; NT-07: Compartimentação Horizontal e Compartimentação Vertical.

Além dessas, têm-se: NT-08: Saídas de Emergência em Edificações; NT-09: Carga de Incêndio nas Edificações e Áreas de Risco; NT-10: Pressurização de Escadas de Segurança de Incêndio; NT-11: Planos de Intervenção de Incêndio; NT-12: Brigada de Incêndio; NT-13: Iluminação de Emergência; NT-14: Sistemas de Deteç̧ão e Alarme de Incêndio; NT-15: Sinalização de Emergência; NT-16: Sistemas de Proteção por Extintores de Incêndio; NT-17: Sistemas de Hidrantes para Combate a Incêndio; NT-18: Sistemas de Chuveiros Automáticos; NT-19: Sistemas de Resfriamento para Líquidos e Gases Inflamáveis e Combustíveis; NT-20: Sistemas de Proteção por Espuma; NT-21: Sistemas Fixos de Gases para Combate a Incêndio; NT-22: Armazenagem de Líquidos Inflamáveis e Combustíveis.

Por fim: NT-23: Manipulação, Armazenamento, Comercialização e Utilização de Gás Liquefeito de Petróleo - GLP; NT-24: Dimensionamento de Lotação e Saídas de Emergência em Recintos Esportivos e de Espetáculos Artístico-Culturais; NT-25: Medidas de Segurança Contra Incêndio em Subestações Elétricas; NT26: Eventos Temporários; NT-27 e NT-28 foram revogadas; NT-29: Cobertura de Sapé, Piaçava e Similares; NT-30: Hidrante Público; NT-31: Condições Necessárias de Segurança Contra Incêndio e Pânico em Edificações Destinadas ao Comércio de Fogos de Artifício no Varejo e Espetáculos Pirotécnicos; e NT-32: Plano de Segurança Contra Incêndio e Pânico - PLAPCIP.

Os trâmites processuais relacionados à regularização pertinente no Estado passam pela submissão do projeto para análise junto ao Corpo de Bombeiros, e após sua aprovação, há uma vistoria in loco para comprovar a execução conforme o projeto, seguindo as prescrições das normas. Entretanto, é constatado que os projetos de segurança contra incêndio e pânico muitas vezes precisam de várias correções até a aprovação. Isso gera prejuízos econômicos ao dono do empreendimento e ao profissional que executa o projeto. Desse modo, a qualificação dos engenheiros civis e arquitetos em relação aos sistemas de segurança contra incêndio, repercute diretamente no andamento dos processos de aprovação dos projetos de combate a incêndio e pânico e até mesmo no andamento dos empreendimentos.

Diante do exposto, o trabalho buscou traçar um diagnóstico acerca da aprovação dos projetos de combate a incêndio e pânico em Porto Nacional (TO), avaliando as dificuldades encontradas pelos profissionais durante todo o processo, além de ter sido feito uma avaliação do conhecimento de formandos e profissionais em Engenharia Civil e Arquitetura quanto ao assunto abordado, para justificar as dificuldades na aprovação dos projetos.

\section{METODOLOGIA}

Tipo de pesquisa e campo temático e coleta de dados

O estudo é caracterizado como uma pesquisa do tipo descritiva, bibliográfica e documental a partir de uma abordagem quantitativa. A pesquisa é centrada no campo da Economia, Planejamento e 
Desenvolvimento Regional, para a prevenção e combate a incêndios. Para a realização da pesquisa, primeiramente foi solicitado ao comandante do Corpo de Bombeiros Militar de Porto Nacional (TO), Capitão Benvindo Filho Pinto de Queiroz, os dados referentes aos trâmites dos processos de projeto de prevenção e combate a incêndio submetidos à Companhia de Porto Nacional (TO) no período de janeiro de 2017 a março de 2019.

Foram selecionados somente os trâmites dos processos de edificações com áreas superiores a $750 m^{2}$, edificações acima de dois pavimentos, locais de reunião de público com lotação acima de 300 pessoas, postos de combustíveis e depósitos pois são critérios de análises e aprovação de Projeto de Prevenção e Combate a Incêndio e Pânico - PPCIP junto ao Corpo de Bombeiros, para posteriormente realizar a análise dos mesmos. Os dados foram disponibilizados no início de abril de 2019, onde foram repassadas 136 análises processos, entretanto 47 se tratavam da aprovação de eventos temporários, restando 89 processos para aprovação de PPCIP. Ainda nesse mesmo mês foi feita a aplicação do questionário referente ao conhecimento dos formandos e profissionais quanto a aprovação dos projetos.

O questionário foi aplicado de modo virtual, a partir das ferramentas disponíveis no Gmail do Google, com 13 perguntas referentes ao conhecimento dos acadêmicos e profissionais sobre elaboração de PPCIP e opinião deles quanto ao assunto, inclusive uma investigação sobre o estudo de PPCIP durante a graduação. Os estudantes e profissionais em Engenharia Civil e Arquitetura foram convidados a responder o questionário por livre e espontânea vontade, e não houve identificação para a preservação da identidade do entrevistado. No total foram feitos 66 questionários virtualmente.

Para a análise dos dados, utilizou-se a linguagem numérica, principalmente por meio de porcentagens geradas em gráficos dos programas Excel e Word do pacote Microsoft Office 2016. As informações do questionário foram analisadas por meio dos gráficos gerados automaticamente para cada pergunta do questionário pelo Google. Para a análise dos dados dos processos para aprovação de PPCIP foi pautada nas normas vigentes do Corpo de Bombeiros Militar do Estado do Tocantins, bem como na Lei no 1.787 de 15 de maio de 2007.

\section{RESULTADOS E DISCUSSÕES}

\section{Projeto de prevenção e combate a incêndio e pânico}

Para o período pesquisado, foram analisados 89 processos de Projeto de Prevenção e Combate a Incêndio e Pânico - PPCIP, incluindo os retornos destes devido aos erros. Entre todas as 89 análises dos processos, há correções sugeridas pelo Corpo de Bombeiros para que o projeto se adeque às normas e seja aprovado. Foi observado que alguns processos tinham mais de 10 correções a serem feitas, conforme a figura 1.

Observa-se que 46\% das análises dos processos obtinham entre 6 e 10 correções propostas, 28\% obtiveram entre 11 e 15 correções, 14\% entre 1 e 5 correções, 7\% entre 16 e 20 correções, 3\% entre 21 e 25, e $2 \%$ acima de 26 correções. São números relativamente altos, que representam a quantidade de erros nos 
Projetos de Prevenção e Combate a Incêndio e Pânico submetidos à aprovação junto ao Corpo de Bombeiros, e expressam o desconhecimento dos profissionais em fazer Projeto de Prevenção e Combate a Incêndio e Pânico.

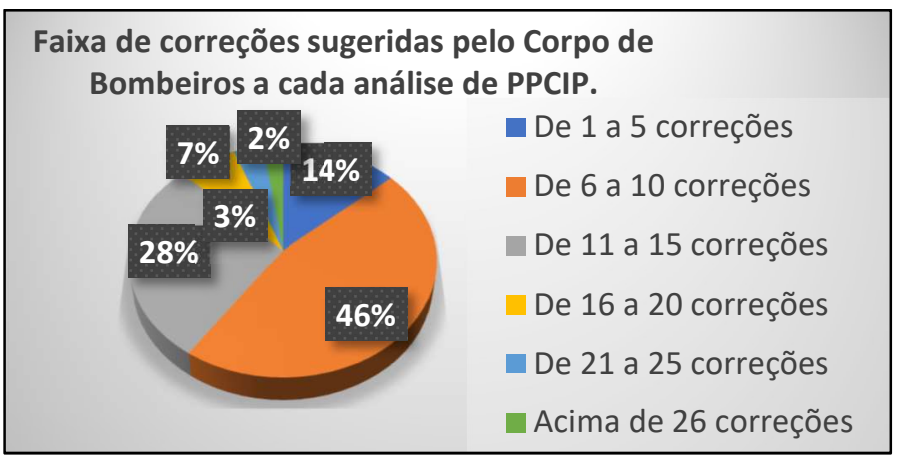

Figura 1: Quantidade de correções sugeridas nas análises dos processos.

Em cada uma das análises dos processos de PPCIP disponibilizadas pelo Corpo de Bombeiros, há a descrição das correções propostas, juntamente às Normas Técnicas que os erros infringem. As principais Normas Técnicas identificadas nos erros dos processos da PPCIP foram: NT-01, NT-08, NT-12, NT-15, NT-16, NT-17 e NT-23, porém também houveram identificações das normas NT-03, NT-04, NT-05, NT-06, NT-07, NT09, NT-11, NT-13, NT-14, NT-19, NT-20, NT-22, NT-24, NT-26, NT-30., conforme as figuras 2, 3 e 4. Em cada documento de correção submetido ao Corpo de Bombeiros pode haver erros que comprometem mais de uma NT.

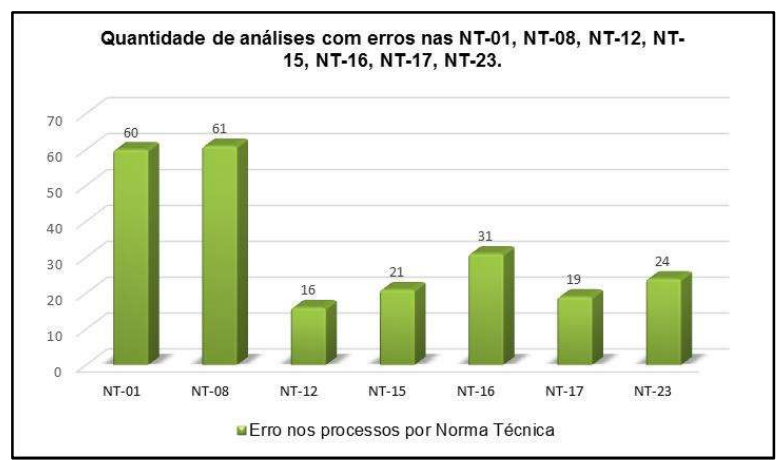

Figura 2: Quantidade de análises com erros nas Normas Técnicas.

É perceptível que as Normas Técnicas 01 e 08 foram infringidas na maioria das análises feitas pelo Corpo de Bombeiros. Do total de 89 análises, 61 delas tiveram erros na NT-08 (Saídas de Emergência em Edificações), isso representa em torno de $68,54 \%$, um valor extremamente alto, que evidencia a falta de conhecimento ou atenção dos profissionais que fazem o PPCIP, principalmente por essa ser uma norma que possui bastante detalhes. Também, do total das 89 análises, 60 infringiram a NT-01 (Procedimentos Administrativos), representando cerca de $67,41 \%$ das análises que tiveram erro nessa norma, um valor bastante alto, assim como para a NT-08.

Os erros referentes à NT-16 (Sistemas de Proteção por Extintores de Incêndio) estiveram em 34,83\% das análises. Referentes à NT-23 (Manipulação, Armazenamento, Comercialização e Utilização de Gás Liquefeito de Petróleo - GLP) estiveram presentes em 26,97\%. Referentes à NT-15 (Sinalização de Emergência) estiveram presentes em 23,59\%, já sobre a, NT-17 (Sistemas de Hidrantes para Combate a Incêndio) em 21,35\%, e NT-12 (Brigada de Incêndio) estiveram presentes em 17,98\% das análises. Os valores 
são altos, e assim como para a NT-01 e NT-08, evidenciam a falta de conhecimento dos profissionais nas Normas Técnicas para fazer Projetos de Prevenção e Combate a Incêndio e Pânico.

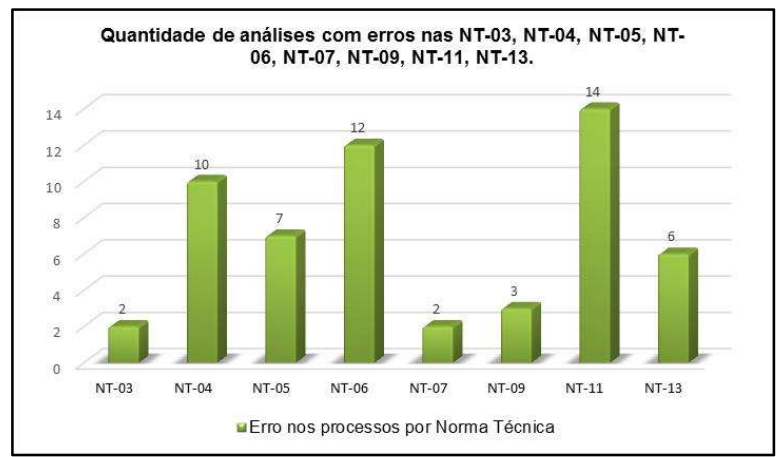

Figura 3: Quantidade de análises com erros nas Normas Técnicas.

Os erros referentes à NT-11 (Planos de Intervenção de Incêndio) representam 15,73\% do total de 89 análises. Referentes à NT-06 (Segurança Estrutural de Edificações) representam 13,48\%. Para a NT-04 (Pressurização de Escadas de Segurança de Incêndio) os erros representam 11,23\% do total. Já a NT-05 (Separação entre Edificações - Isolamento de Risco) possui erros em 7,86\% do total. Para a NT-13 (Iluminação de Emergência) há 6,74\% de erros.

Para a NT-09 (Carga de Incêndio nas Edificações e Áreas de Risco) há 3,37\% de erros, e para a NT-03 (Símbolos Gráficos para Projetos de Segurança contra Incêndio e Pânico) e NT-07 (Compartimentação Horizontal e Compartimentação Vertical) há somente 2,24\% de erros para cada do total. Os valores não são muito altos para essas Normas Técnicas, entretanto poderiam ser ainda menores mediante um estudo aprofundado sobre as normas, e uma verificação de todo o projeto junto às normas antes de submeter ao Corpo de Bombeiros para aprovação.

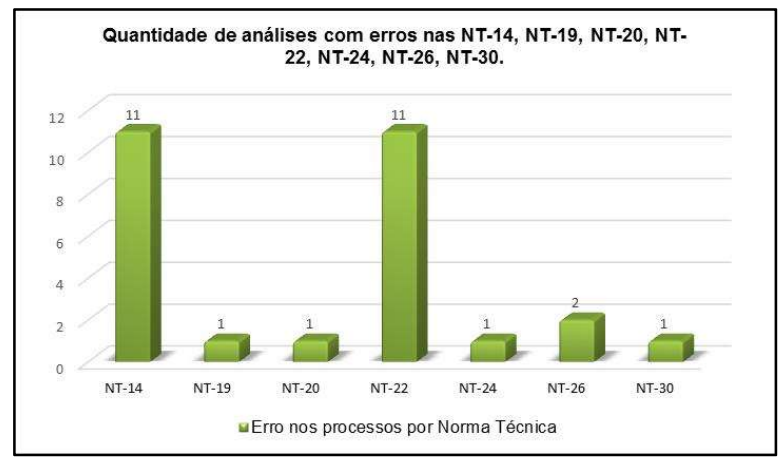

Figura 4: Quantidade de análises com erros nas Normas Técnicas.

Os erros para a NT-14 (Sistemas de Detecção e Alarme de Incêndio) e NT-22 (Armazenagem de Líquidos Inflamáveis e Combustíveis) representam 12,35\% cada em relação ao total. Referentes à NT-26 (Eventos Temporários) há 2,24\% do total de 89 análises, e apesar de não haver análise para eventos temporários, há Projetos de Prevenção e Combate a Incêndio e Pânico para clubes que realizam eventos.

Para as NT-19 (Sistemas de Resfriamento para Líquidos e Gases Inflamáveis e Combustíveis), NT-20 (Sistemas de Proteção por Espuma), NT-24 (Dimensionamento de Lotação e Saídas de Emergência em Recintos Esportivos e de Espetáculos Artístico-Culturais) e NT-30 (Hidrante Público) houve 1,12\% do total 
para cada. A porcentagem de erros para essas Normas Técnicas não é muito alta, porém assim como nas outras poderia ser diminuída.

De um modo geral, os erros existentes para cada Norma Técnica em relação às 89 análises, estão descritos na figura 5, organizados em ordem crescente de acordo com a maior incidência de erros para as normas, e evidencia o quanto a NT-08 e a NT-01 tiveram erros notificados conforme as mesmas, onde cada possui quase $70 \%$ das notificações de erros.

\begin{tabular}{|l|r|}
\hline Norma Técnica & Porcentagem \\
\hline NT-08 & $68,54 \%$ \\
NT-01 & $67,41 \%$ \\
NT-16 & $34,83 \%$ \\
NT-23 & $26,97 \%$ \\
NT-15 & $23,59 \%$ \\
NT-17 & $21,35 \%$ \\
NT-12 & $17,98 \%$ \\
NT-11 & $15,73 \%$ \\
NT-06 & $13,48 \%$ \\
NT-14 & $12,35 \%$ \\
NT-22 & $12,35 \%$ \\
NT-04 & $11,23 \%$ \\
NT-05 & $7,86 \%$ \\
NT-13 & $6,74 \%$ \\
NT-09 & $3,37 \%$ \\
NT-03 & $2,24 \%$ \\
NT-07 & $2,24 \%$ \\
NT-26 & $2,24 \%$ \\
NT-19 & $1,12 \%$ \\
NT-20 & $1,12 \%$ \\
NT-24 & $1,12 \%$ \\
NT-30 & $1,12 \%$ \\
\hline
\end{tabular}

Figura 5: Resumo da porcentagem de erros por norma nas análises de PPCIP.

Desse modo percebe-se que a NT-08 foi a norma que esteve mais presente nos erros das 89 análises, com $68,54 \%$ ou presente em 61 das 89 no total. Para a NT-01 esse valor é bem próximo, com $67,41 \%$ ou 60 das 89 análises. Para a NT-16 há 34,83\% ou em 31 das 89 análises. Para a NT-23 há 26,97\%, ou em 24 do total. Para a NT-15, com $23,59 \%$ ou 21 do total. Para a NT-17 há $21,35 \%$ ou em 19 do total. Para as outras Normas Técnicas o valor fica abaixo de 20\%, sendo que para as NT-19, NT-20, NT-24 e NT-30 estão presentes em apenas $1,12 \%$ do total. Não foram identificados erros embasados nas NT-02, NT-10, NT-18, NT-21, NT25, NT-29, NT-31 e NT-32.

Cabe ressaltar a predominância de erros referentes às NT-01, NT-08, NT-15, NT-16 e NT-17, que tratam dos detalhes dos projetos, como placas, iluminações, extintores, hidrantes etc., fundamentais para a realização de qualquer Projeto de Prevenção e Combate a Incêndio e Pânico. Também há uma predominância de erros referentes às NT-22 e NT-23, por se tratar de Líquidos Inflamáveis, Combustíveis e Gás Liquefeito de Petróleo, devido as muitas submissões de aprovação de projetos de depósitos de gás e postos de combustíveis.

Muitos dos erros identificados nos projetos também se referiam à detalhes de projeto, como falta de dimensões na planta baixa, repetições, falta de descrição dos ambientes, falta de nível, etc.. Além das Normas Técnicas, foi identificado que em 12 das 89 análises de processos de PPCIP houve erros referentes à Lei no $1.787 / 2007$, o que representa $13,48 \%$, um número não muito alto, porém demonstra a importância de ter conhecimento sobre a referida lei. 


\section{Questionários aos formandos e profissionais}

Como modo de explicar os possíveis erros existentes para a aprovação dos Projetos de Prevenção e Combate a Incêndio e Pânico, um questionário para analisar o conhecimento dos formandos e profissionais sobre o assunto foi aplicado a 66 pessoas, tanto para a área de Engenharia Civil, quanto para a Arquitetura e Urbanismo. Em torno de $56,1 \%$ das pessoas que responderam ao questionário são do sexo masculino, 42,4\% do sexo feminino e $1,5 \%$ preferiu não responder sobre seu sexo. Cerca de $54,5 \%$ das pessoas possuem a faixa etária entre 22 e 30 anos, 21,2\% entre 18 e 22 anos, 13,6\% acima de 35 anos e 10,6\% entre 30 e 35 anos. Do total de questionários respondidos, verificou-se que em torno de 83\% das pessoas são da área de Engenharia Civil e $17 \%$ são da Arquitetura e Urbanismo, conforme a figura 6, devido a melhor facilidade e proximidade para realizar pesquisas com o público da Engenharia Civil. Desse público, 50\% já estão formados e 50\% estão entre o 8 ㅇ e 10을 dos cursos de engenharia civil ou arquitetura, conforme a figura 7.

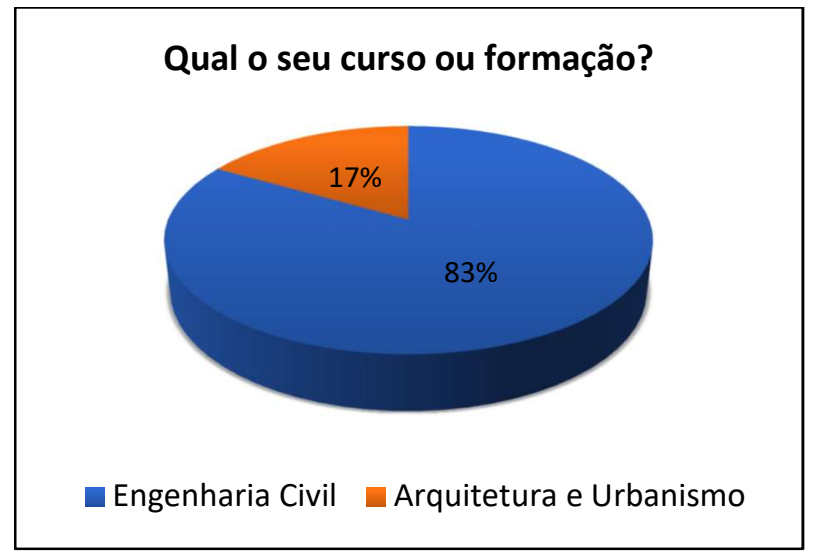

Figura 6: Curso ou formação dos pesquisados.

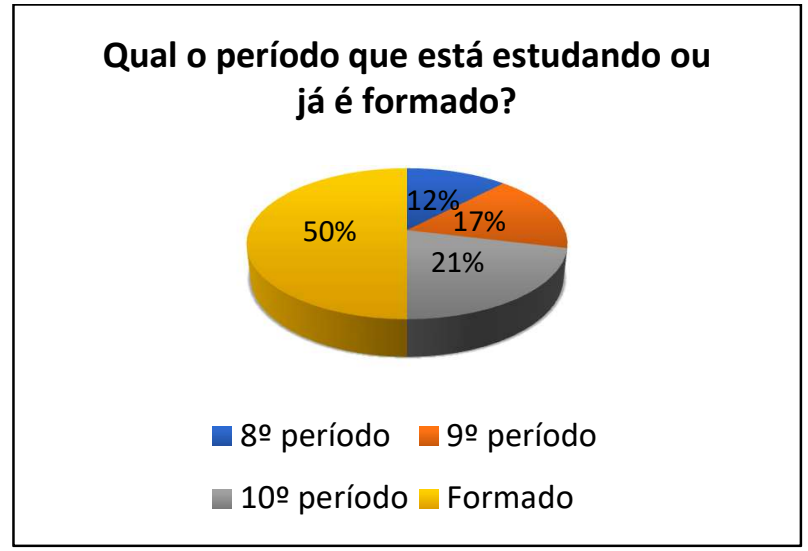

Figura 7: Período de estudo e quantidade de formados.

Em torno de 46,2\% daqueles que responderam ao questionário são estudantes formandos, deste total, cerca de 15,4\% estão formados entre 0 e 6 meses, 12,3\% estão formados há mais de 3 anos, 10,8\% estão formados entre 1 a 2 anos, 9,2\% estão formados entre 6 meses e 1 ano e 6,2\% estão formados entre 2 e 3 anos. Logo, percebe-se que a maior parte ainda não é profissional, e outra grande parte possui pouco tempo de formado.

Ao serem questionados sobre a lei que rege as regulamentações referentes a Projetos de Prevenção e Combate a Incêndio e Pânico no Estado do Tocantins (Lei 1.787/2007), cerca de 40,9\% responderam que conhecem pouco sobre ela, 37,9\% disseram conhecer, e $21,2 \%$ disseram não conhecer. O valor de quem conhece a lei é relativamente pequeno.

Além disso, em torno de 48,5\% respondeu não saber a quantidade das normas técnicas para a elaboração de PPCIP, 37,9\% disseram conhecer algumas, e apenas 13,6\% disseram ter conhecimento sobre todas. E 53\% já tiveram acesso à legislação de segurança contra incêndio e pânico do Estado do Tocantins, enquanto $47 \%$ ainda não tiveram acesso. Em contrapartida, em torno de $69,7 \%$ sabem onde encontrar essa legislação, e 30,3\% não sabem onde encontrar. Ao serem questionados sobre quando elaborar um Projeto de Prevenção e Combate a Incêndio e Pânico, mais de 50\% dos entrevistados responderam de forma errônea, e somente $43 \%$ sabem quando deve ser elaborado, conforme a figura 7. 


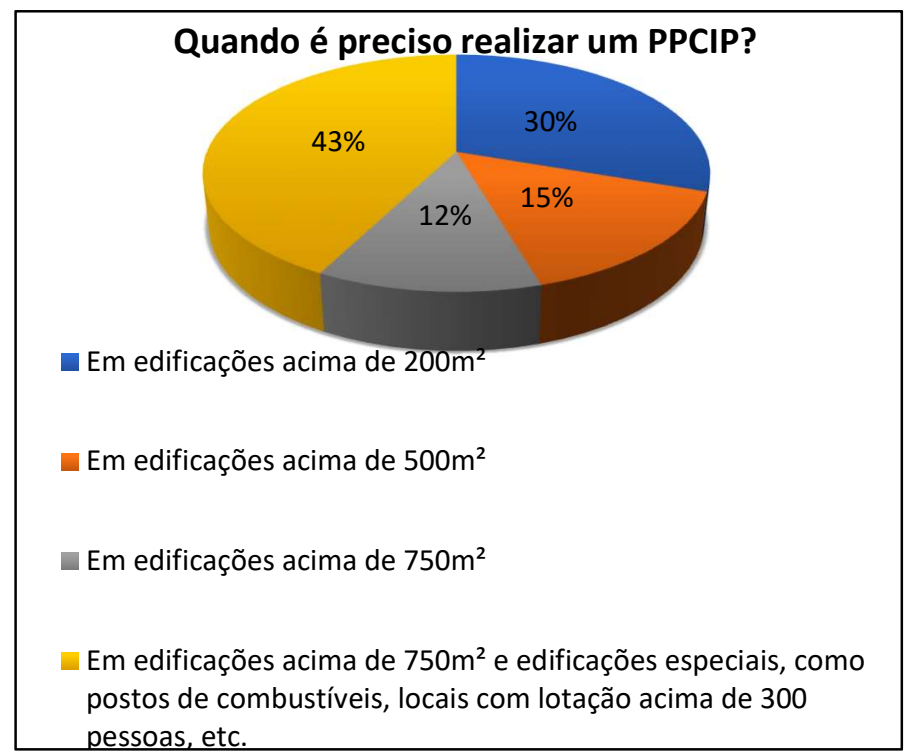

Figura 7: Quando um PPCIP deve ser elaborado.

De acordo com as Normas do Corpo de Bombeiros do Estado do Tocantins, o PPCIP deve ser realizado em edificações acima de $750 \mathrm{~m}^{2}$, com mais de dois pavimentos, com lotação acima de 300 pessoas, edificações com armazenamento de líquidos combustíveis e inflamáveis, depósitos de gás de grande porte (com mais de 120 botijões de $13 \mathrm{~kg}$ ou acima de $1.560 \mathrm{~kg}$ de armazenamento de gás), locais com central de GLP, locais que possuem caldeira, etc., onde condições inferiores a essa solicita a realização do PLAPCIP, regulamentado pela Norma Técnica no 32. Um valor bastante alto por se tratar de estudantes e profissionais que já estudaram sobre o assunto.

No que se refere à experiência, quanto a elaboração de PPCIP, cerca de 51,5\% tiveram somente por meio da elaboração de trabalhos acadêmicos durante a graduação, 25,8\% já tiveram experiência profissionalmente, e 22,7\% ainda não tiveram nenhuma experiência, nem mesmo na graduação, conforme a figura 8. Apenas $22,7 \%$ do público entrevistado acredita ter conhecimento suficiente para elaborar um PPCIP, $42,4 \%$ disseram que talvez possuam conhecimento para tal, e $34,8 \%$ afirmam não ter conhecimento suficiente para isso, conforme é mostrado na figura 9.

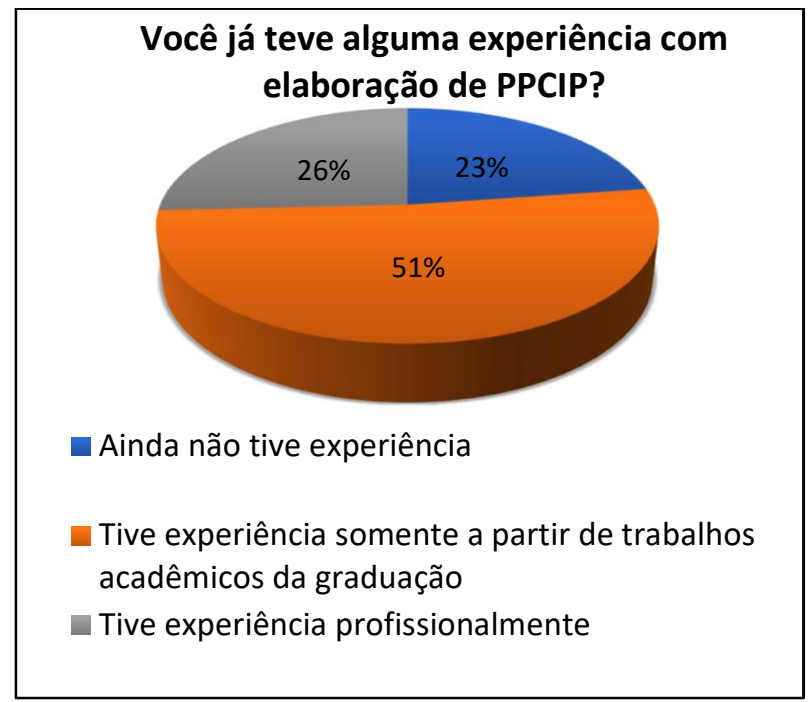

Figura 8: Experiência na elaboração de PPCIP.

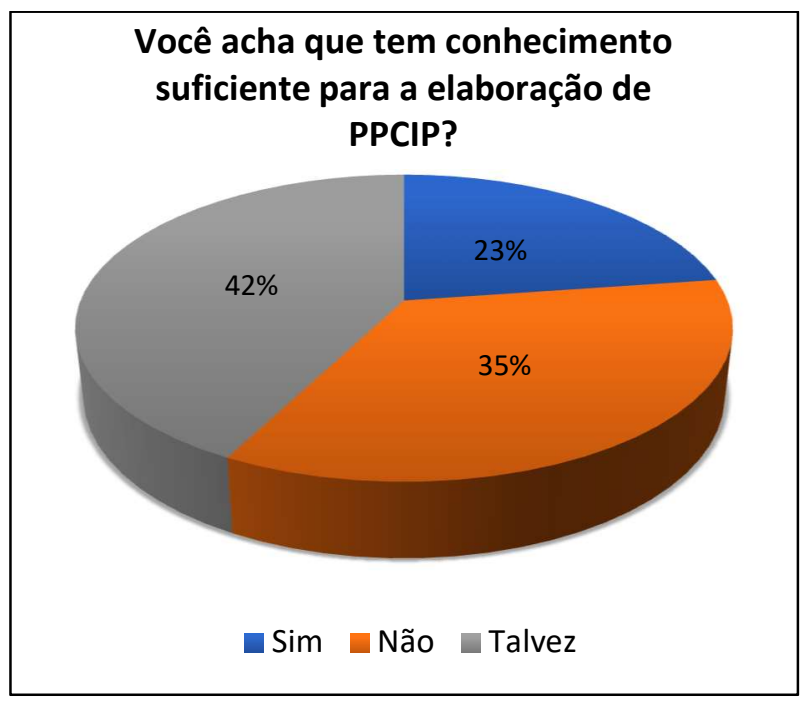

Figura 5: Conhecimento para a elaboração de PPCIP. 
Aliado a isso, 69,7\% acreditam que os conhecimentos adquiridos na faculdade não são suficientes para a aplicabilidade na prática de um PPCIP, enquanto $21,2 \%$ acreditam que somente talvez esse conhecimento seja suficiente, e somente $9,1 \%$ acreditam ser suficiente, conforme a figura 10 . E isso evidencia que é necessário que as faculdades priorizem mais no ensino da segurança. Porém, existem especializações referentes à segurança no trabalho que foca sobre essa temática de projetos de combate a incêndio.

Para aqueles que já elaboraram um PPCIP, mesmo que somente durante trabalhos acadêmicos, $31,7 \%$ disseram que tiveram dificuldades no sistema de hidrantes, 6,7\% tiveram dificuldades com os extintores, $5 \%$ tiveram dificuldades com placas de sinalização, 36,7\% disseram que tiveram dificuldade com tudo, tanto com hidrantes, quanto com extintores e placas, e somente $20 \%$ disseram que não houve dificuldade, conforme a figura 11.

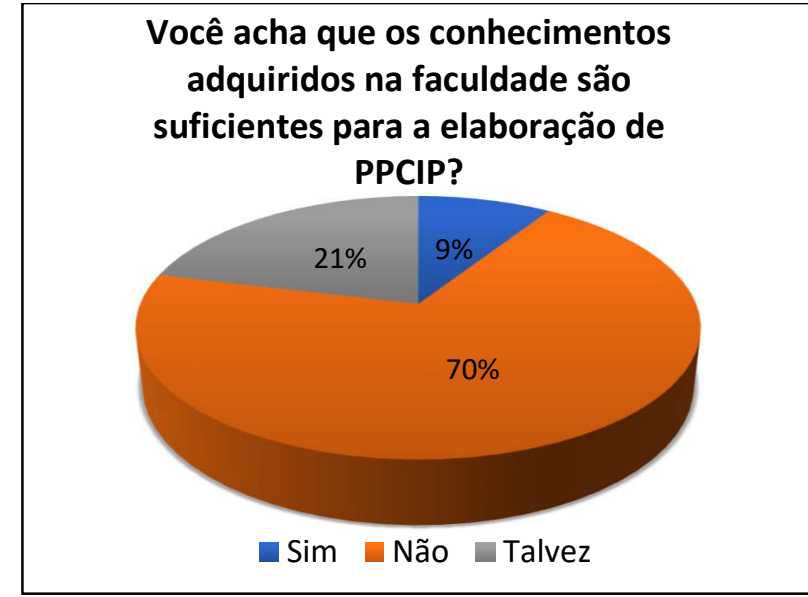

Figura 10: Opinião sobre os conhecimentos adquiridos na graduação para a elaboração de PPCIP.

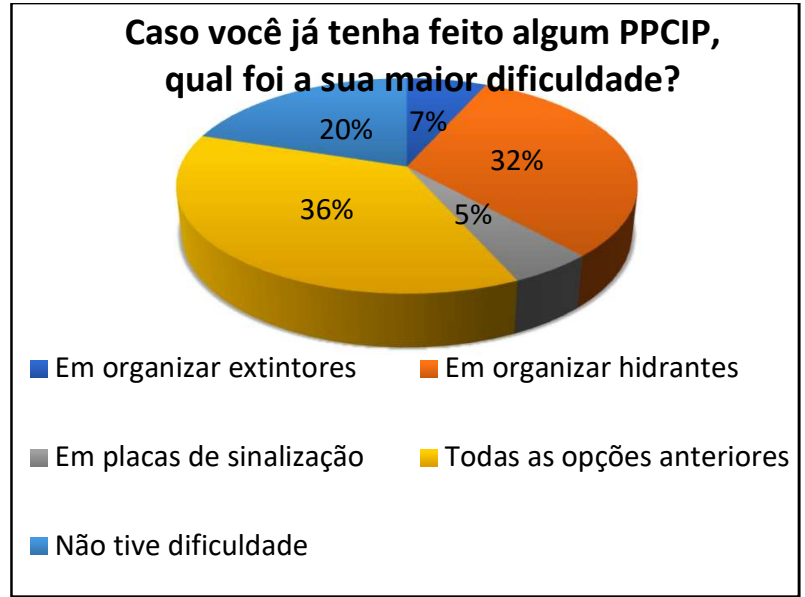

Figura 11: Dificuldade na elaboração de PPCIP.

Desse modo percebe-se que há uma falta de conhecimento muito grande por parte dos estudantes de Engenharia e Arquitetura, e até mesmo dos profissionais dessas áreas, que são aqueles que podem elaborar um PPCIP, devido ao estudo referente a isso durante a graduação. Entretanto, a maioria dos pesquisados acreditam que os conhecidos adquiridos na graduação não são suficientes para elaborar um PPCIP, e desse modo a maioria não se acha apto a elaborar, e aqueles que já elaboraram, somente poucos não tiveram dificuldade.

\section{CONCLUSÕES}

A partir do pesquisado e analisado, percebe-se que os Projetos de Prevenção e Combate a Incêndio e Pânico submetidos à aprovação do Corpo de Bombeiros de Porto Nacional (TO) possuem muitos erros, infringindo muitas das Normas Técnicas, principalmente a NT-01 e NT-08, por se tratar de normas gerais para todos os tipos de projetos. Também houve uma predominância muito alta de erros que infringem a NT-22 e NT-23, devido a haver muitos projetos de depósitos de gás e postos de combustíveis, pois o Corpo de Bombeiros de Porto Nacional (TO) atende às cidades vizinhas, como os municípios de Mateiros, Silvanópolis, Brejinho de Nazaré, Monte do Carmo, Silvanópolis, Ponte Alta do Tocantins, Arraias e Santa Rosa. Poucos 
foram as análises de PPCIP que não tiveram erros que infringiam as Normas Técnicas, pois em algumas os erros eram só referentes a detalhes de projeto, como falta de cotas, falta de nível, etc..

Houveram análises com mais de 26 correções propostas pelo Corpo de Bombeiros, um número muito alto, onde tudo isso evidencia a falta de conhecimento dos profissionais que elaboram o PPCIP, pois com mais atenção e estudo nas Normas Técnicas esses erros poderiam ser reduzidos. Isso é verificado a partir do questionário aplicado a estudantes formandos e profissionais de Engenharia Civil e Arquitetura, onde grande parte desconhece as normas técnicas, e aqueles que já tiveram experiência em elaborar um PPCIP boa parte teve dificuldade. Além disso, a grande maioria diz não ter conhecimento suficiente para elaborarem um PPCIP, e acreditam que os conhecimentos adquiridos na faculdade não são suficientes para a aplicabilidade prática na elaboração de um PPCIP.

Desse modo, percebe-se que deve haver um maior estudo referente às Normas Técnicas para que muitos erros na aprovação de um PPCIP sejam evitados, tanto por parte dos estudantes e profissionais, quanto por parte das Instituições de Ensino de Engenharia Civil e Arquitetura que devem procurar melhores metodologias para o ensino de Engenharia de Segurança.

\section{REFERÊNCIAS}

FAGUNDES, F.. Plano de Prevenção e Combate a Incêndios: estudo de caso em edificação residencial multipavimentada. Santa Maria: UNIJUÍ, 2013.

GALVÃO, A. F.. A importância do Projeto de Prevenção e Combate a Incêndios para a qualidade e segurança das edificações: pesquisa de campo na cidade de Boa Esperança - ES. Vitória: Faculdade Multivix, 2018.

GOMES, Taís. Projeto de Prevenção e Combate a Incêndio. Santa Maria: UFMS, 2014.

PORTUGAL, D. N. M.. Análise das instalações de proteção contra incêndio em conjunto de barracões comerciais na cidade de Curitiba. Curitiba: UTFPR, 2014.
ROCHA, A. C. B. Q.. Análise das instalações de proteção e combate a incêndio de uma edificação pública. Natal: UFRN, 2016.

SILVA, E. P.; PICCININI, Â. C.. Projeto preventivo de incêndio de um supermercado em SC, comparando com as legislações dos demais estados do sul do Brasil. Criciúma: UNESC, 2017.

TOCANTINS. Lei Estadual n.1787 de $\mathbf{1 5}$ de maio de 2007. Palmas: DOE, 2007.

A CBPC - Companhia Brasileira de Produção Científica (CNPJ: 11.221.422/0001-03) detém os direitos materiais desta publicação. Os direitos referem-se à publicação do trabalho em qualquer parte do mundo, incluindo os direitos às renovações, expansões e disseminações da contribuição, bem como outros direitos subsidiários. Todos os trabalhos publicados eletronicamente poderão posteriormente ser publicados em coletâneas impressas sob coordenação da Sustenere Publishing, da Companhia Brasileira de Produção Científica e seus parceiros autorizados. Os (as) autores (as) preservam os direitos autorais, mas não têm permissão para a publicação da contribuição em outro meio, impresso ou digital, em português ou em tradução. 